\title{
Lipochitin Oligosaccharides Immobilized through Oximes in Glycan Microarrays Bind LysM Proteins
}

\author{
Nicolai N. Maolanon, ${ }^{[a, d]}$ Mickael Blaise, ${ }^{[b, d]}$ Kasper K. Sørensen, ${ }^{[a, d]}$ Mikkel B. Thygesen, ${ }^{[a, d]}$ \\ Emiliano Cló, ${ }^{[a]}$ John T. Sullivan, ${ }^{[c, d]}$ Clive W. Ronson, ${ }^{[c, d]}$ Jens Stougaard, ${ }^{[b, d]}$ Ola Blixt, ${ }^{[a]}$ and \\ Knud J. Jensen ${ }^{*[a, d]}$
}

\begin{abstract}
Glycan microarrays have emerged as novel tools to study carbohydrate-protein interactions. Here we describe the preparation of a covalent microarray with lipochitin oligosaccharides and its use in studying proteins containing LysM domains. The glycan microarray was assembled from glycoconjugates that were synthesized by using recently developed bifunctional chemoselective aminooxy reagents without the need for transient carbohydrate protecting groups. We describe for the first time the preparation of a covalent microarray with lipochitin oligosaccharides and its use for studying proteins containing LysM domains. Lipochitin oligosaccharides (also referred to as Nod factors) were isolated from bacterial strains or chemoenzymatically synthesized. The glycan microarray also included
\end{abstract}

peptidoglycan-related compounds, as well as chitin oligosaccharides of different lengths. In total, 30 ligands were treated with the aminooxy linker molecule. The identity of the glycoconjugates was verified by mass spectrometry, and they were then immobilized on the array. The presence of the glycoconjugates on the array surface was confirmed by use of lectins and human sera (IgG binding). The functionality of our array was tested with a bacterial LysM domain-containing protein, autolysin p60, which is known to act on the bacterial cell wall peptidoglycan. P60 showed specific binding to Nod factors and to chitin oligosaccharides. Increasing affinity was observed with increasing chitin oligomer length.

\section{Introduction}

Glycobiology, in particular the study of carbohydrate-protein interactions and the events that follow, has become an important research focus in recent decades. Preparation of homogeneous carbohydrate ligands in suitable amounts for studying such interactions is one of the technological challenges of glycobiology. ${ }^{[1]}$ As carbohydrates are secondary gene products, they are difficult to express in microorganisms by conventional molecular biological methods. Chemical synthesis is complicated due to the complexity of carbohydrate structures, including linkage positions and anomeric configurations, as well as branching in many cases. ${ }^{[2]}$ The interest in glycobiology reflects

[a] Dr. N. N. Maolanon, Dr. K. K. Sørensen, Prof. M. B. Thygesen, Dr. E. Cló, Prof. O. Blixt, Prof. K. J. Jensen

Department of Chemistry, Faculty of Science, University of Copenhagen Thorvaldsensvej 40, 1871 Frederiksberg C (Denmark) E-mail:kjj@chem.ku.dk

[b] Dr. M. Blaise, Prof. J. Stougaard

Department of Molecular Biology and Genetics, Aarhus University Gustav Wieds Vej 10, 8000 Aarhus C (Denmark)

[c] Dr. J. T. Sullivan, Prof. C. W. Ronson

Department of Microbiology and Immunology, University of Otago 720 Cumberland Street, Dunedin 9054 (New Zealand)

[d] Dr. N. N. Maolanon, Dr. M. Blaise, Dr. K. K. Sørensen, Prof. M. B. Thygesen, Dr. J. T. Sullivan, Prof. C. W. Ronson, Prof. J. Stougaard, Prof. K. J. Jensen Centre for Carbohydrate Recognition and Signalling University of Copenhagen Thorvaldsensvej 40, 1871 Frederiksberg C (Denmark)

Supporting information for this article is available on the WWW under http://dx.doi.org/10.1002/cbic.201300520. the various important biological roles in which carbohydrates are involved. Central elements include cell-cell recognition events that mediate immune responses, ${ }^{[3]}$ post-translational glycosylations that alter protein properties, ${ }^{[4]}$ and other signaling processes that occur between cells and even between different organisms. One example of a key biological system that is initiated through a complex molecular signaling network is legume-rhizobium symbiosis. ${ }^{[5]}$ The initial communication between plant host and bacteria is facilitated by lipochitin oligosaccharide signaling molecules known as Nod factors. ${ }^{[5]}$ The putative Nod factor receptors located in the host plant root hairs have extracellular LysM domains. ${ }^{[6]}$ These domains are also found in certain chitinases ${ }^{[7]}$ and peptidoglycan binding proteins. ${ }^{[8]}$ The glycan microarray described below was developed to investigate interactions involving LysM domain-containing proteins.

LysM domain-containing proteins play important biological roles; however, only a few studies of these carbohydrate-binding proteins have been reported. Although LysM domains have been reported for all kingdoms except Archaea, ${ }^{[9]}$ only one bacterial LysM domain structure has been solved by $\mathrm{NMR}^{\left[{ }^{[9]}\right.}$ and the crystal structure of another, YkuD, which contains a LysM domain, has been solved at high resolution $(2 \AA) .^{[10]}$ These structures have laid the basis for modeling studies. ${ }^{[11]}$ Recently, Arabidopsis thaliana CERK1 (plant immune receptor) has been cocrystallized with chitin, revealing the first LysM-ligand binding site. ${ }^{[12]}$ Most recently, the structure of the fungal Ecp6 protein has been determined, and an additional 
high affinity binding site has been identified. ${ }^{[13]}$ LysM binding constants have very recently been determined ${ }^{[14]}$ by use of surface plasmon resonance techniques. The remainder of the reported LysM domains have been predicted based on amino acid sequences, ${ }^{[15]}$ and several of these proteins are of unknown function. A better understanding of this group of proteins could therefore lead to enhanced insight into biological processes in a wide range of organisms.

Glycan microarrays have recently emerged as a technology for unraveling glycan-protein interactions. ${ }^{[16]}$ Starting in 2004, the Consortium for Functional Glycomics (CFG) developed an elaborate glycan array containing more than 600 ligands, including many complex carbohydrate antenna structures as first reported by Blixt et al. ${ }^{[17]}$ This relied on multi-step syntheses to obtain the glycoconjugates. More recent studies have paved the way for on-surface enzymatic syntheses of the carbohydrate ligands, ${ }^{[18]}$ analysis of immobilized ligands by MALDITOF-MS on the surface, ${ }^{[19]}$ and even evaluation of binding constants. ${ }^{[20]}$

The total synthesis of complex glycoconjugates generally requires many chemical steps with a significant number of protecting group conversions. Glycan microarrays (glycochips), in theory, should be able to present glycans, including glycans isolated from naturally occurring specimens, in a biologically meaningful fashion. Several approaches to covalent glycochips have been described in recent years. Most protocols require the carbohydrate probes to be constructed through a multistep synthesis in order to fashion them with the spacer moiety able to react with the solid support of choice. Alternatively, glycan-linker conjugates can be constructed directly by using highly chemoselective reactions between the aldehyde of native, underivatized glycans and a bifunctional linker. They can then be characterized and subsequently coupled to microarray surfaces. A less common approach is the use of reactive functionalized surfaces for direct immobilization of glycans. ${ }^{[21]}$ Strong $\alpha$-nucleophiles such as hydrazines, hydrazones, sulfonylhydrazides, and hydroxylamines have been used. ${ }^{[22]}$ Some glycochips have already been designed to take advantage of these chemoselective couplings. ${ }^{[23]}$

The thermodynamic stability of addition products between aldehydes and $\alpha$-nucleophiles is known to be highest for products formed from aminooxy nucleophiles. ${ }^{[24]}$ Also, N-alkyl substituted aminooxy moieties can direct the stereochemistry at the reducing unit of the saccharide towards the retention of the ring-closed pyranose structure (either exclusively, as with glucose, or predominantly, as with mannose and galactose). ${ }^{[25]}$ However, this comes at the cost of slower formation and lower stability of the conjugate. When interrogating glycans, especially shorter oligosaccharides, it is of crucial importance for functional recognition by proteins that the reducing end is present in the ring-closed form. ${ }^{[26]}$ However, it is important to realize that Nod factors naturally have a free, that is, nonglycosidic, reducing end, which is likely in equilibrium between the ring-closed and ring-open forms. Reaction of the Nod factor with the AMB aminooxy linker will generate a carbohydrate oxime, which is also in equilibrium between the closed and open forms. Several examples of glycoconjugates with carbo- hydrate oximes have previously been reported for neoglycolipid probes absorbed onto nitrocellulose microarrays ${ }^{[27]}$ and by Thygesen, Sauer, and Jensen ${ }^{[28]}$ for gold nanoparticles.

We have previously developed a series of chemoselective bifunctional linkers allowing solution-phase glycan-linker formation and subsequent covalent attachment onto a slide with activated esters. ${ }^{[23,29]}$ Both the aminooxy and the $\mathrm{N}$-alkyl aminooxy versions of these linkers formed a sufficient proportion of ring-closed glycan-linker conjugates for recognition in a microarray. Importantly, we also observed that the dynamic equilibrium between open and closed forms of unsubstituted carbohydrate oximes can be shifted towards the closed form by binding to proteins. ${ }^{[28]}$ Here, two of these linkers were evaluated for the first time in the reaction with rhizobial Nod factors. However, in the reaction with chitin oligosaccharides, only the aminooxy compound provided satisfactory conversion of the glycanlinker conjugate.

Glycochips represent a promising tool for investigating Nod factor receptor specificity and thereby advancing knowledge of the specificity of signaling in legume-rhizobium symbiosis. We present here the first application of these bifunctional linker reagents for the construction of glycan microarrays with complex carbohydrates. The carbohydrate ligands obtained for immobilization on the glycochip described here were chosen based on predictions derived from the known or expected binding capacities of LysM domains. The ligands fall into three categories: chitin oligosaccharides, peptidoglycan (PGN)-related compounds, and Nod factor variants. Thirty ligands were obtained and immobilized as glycoconjugates to form an array. Their presence on the array surface was verified by binding with lectins and human IgG. For initial demonstration of the efficacy of the array, the LysM protein p60, known to process bacterial cell wall PGN, was chosen. This represents the first analysis of a LysM domain protein on a glycan microarray.

\section{Results and Discussion}

The carbohydrate ligands obtained for immobilization on the present microarray fall into three categories: the chitin oligosaccharides, the PGN-related compounds, and a range of Nod factor variants. The first step was to obtain a range of lipochitin oligosaccharides, as well as other carbohydrates and PGNrelated compounds. These were then chemoselectively converted into glycoconjugates by using our $\mathrm{N}$-(2-aminoethyl)-4(aminooxymethyl)benzamide ${ }^{[29]}$ (AMB) reagent, which provided a free amine ready for printing on an activated array surface, as well as the partially ring-closed structure, which mimics the natural compounds. The chitin oligomers, Nod factors, and PGN-related structures were synthesized or extracted from bacterial cultures when commercial products were unavailable.

The glycoconjugates were purified on a hydrophilic interaction chromatography (HILIC) column. The bifunctionality of the AMB linker allowed the hydroxylamine to react with the reducing end (aldehyde) of any unprotected reducing carbohydrate in aqueous solution. A key advantage of the linker is its chromogenic properties, which enable easy visualization and quantification. The resulting carbohydrate linker conjugate exists in 
equilibrium between the open and closed forms (Scheme 2). The ratio of open versus closed form depends on the glycan to which the aminooxy linker is attached. On the array presented in this paper, the reducing end carbohydrate forming the oxime is GlcNAc in most cases. The ratio of open versus closed forms in the cases of LaCNAC, $^{[30]} \mathrm{GlCNAC}^{[31]}$ and $(\mathrm{GlC})_{1-3}{ }^{[28]}$ has been reported to be $8: 1,7: 3$, and $4: 1$, respectively. This correlates well with the AMB linker conjugates obtained (data not shown) and is a feature to be considered when interpreting binding data. The glycoconjugate, for example, GlcNAc-AMB, was designated $\mathbf{1 A}$ to indicate the linker attachment to GlcNAc, 1.

\section{Nod factor isolation}

Nod factors are lipochitin oligosaccharides (LCOs). As the name implies, the backbone is composed of GlcNAc assembled by $\beta(1 \rightarrow 4)$ linkages in lengths of three to six units. ${ }^{[5]}$ The lipid chain is situated at the nonreducing end. Additional chemical groups are located mainly at the terminal residues and vary between rhizobial strains (Scheme 1). Nod factors used in this study are listed in Table 1.

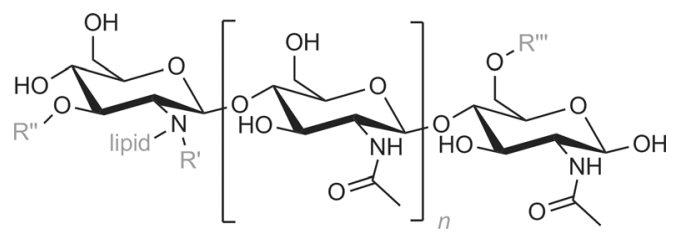

Scheme 1. Generic Nod factor structure. The systematic name for a Nod factor is Nod-n+II( $R^{\prime}, R^{\prime \prime}$, lipid, $\left.R^{\prime \prime \prime}\right)$, as suggested by Heidstra and Bisseling. ${ }^{[32]}$ Nod indicates that it is a Nod factor molecule, and the Roman numeral corresponds to the number of GICNAC units in the chitin backbone. The chemical ornamentations and lipid chain are indicated in brackets. Those to the left of the lipid chain indication are situated at the nonreducing end ( $R^{\prime}$, methyl, and $\mathrm{R}^{\prime \prime}$, carbamoyl in the M. loti Nod factor) of the chitin oligomer, whereas those to the right ( $\mathrm{R}^{\prime \prime \prime}$, acetyl-fucosyl in the $M$. loti Nod factor) are located at the reducing end terminus.

These modifications are thought to determine species-specific recognition most likely mediated by the Nfr 1 and Nfr5 receptor kinases described for Lotus japonicus roots and homologous receptors found in other legumes. ${ }^{[33,34]}$ Nod factors were
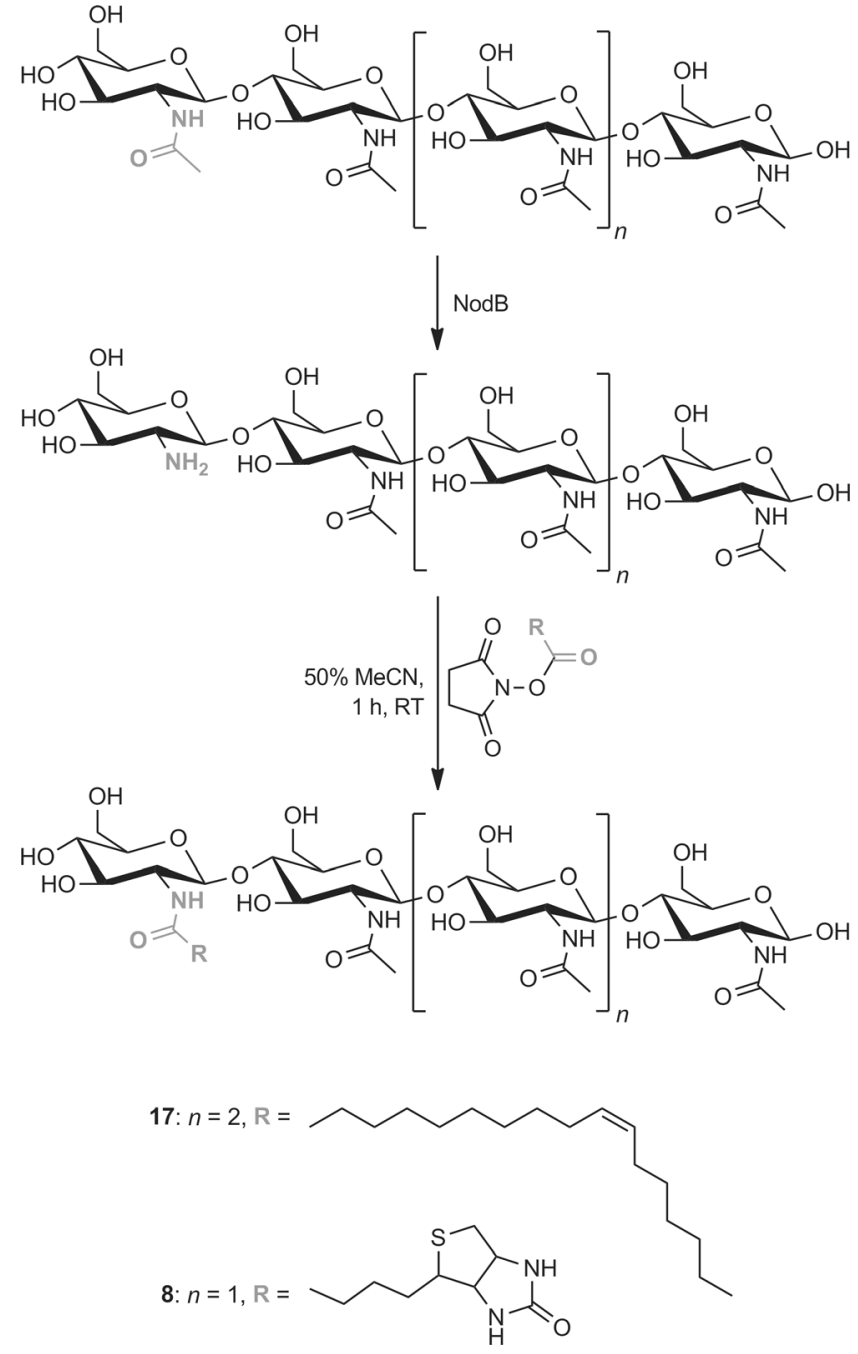

Scheme 2. Chemoenzymatic synthesis of a Nod factor and a biotinylated chitotetraose.

extracted and purified from the Mesorhizobium loti strain $\mathrm{R} \mathrm{A}^{[35]}$ and mutants derived from this strain. To obtain the Nod factors, M. loti growth media was extracted with butanol after removal of the cells, then evaporated and further purified by reversed-phase chromatography. All Nod factor products were verified by mass spectrometry. The characteristic fragmentation pattern arose from the cleavage of glycosidic bonds, which

\begin{tabular}{|c|c|c|}
\hline Chitin & $(\mathrm{GlcNAC})_{8}(7)$ & Nod factors ${ }^{[b]}$ \\
\hline GlcNAc (1) & $(\mathrm{GlcNAc})_{4}$-biotin (8) & NodMI.R7Awt-V(Me,Cb,C18:1,Fuc,Ac) (13) \\
\hline$(\mathrm{GlcNAc})_{2}(2)$ & controls & NodMI.R7Awt-V(Me,Cb,C18:0,Fuc,Ac) (14) \\
\hline$(\mathrm{GlcNAC})_{3}(3)$ & cellotetrose (9) & NodMI.R7Awt-V(Me,Cb,C18:1,Fuc) (15) \\
\hline$(\mathrm{GlcNAc})_{4}(4)$ & maltotetrose (10) & NodMI.R7Awt-V(Me,Cb,C16:0,Fuc,Ac) (16) \\
\hline$(\mathrm{GlcNAc})_{5}(5)$ & $N$-stearyl-GlcN (11) & Nod-V(C18:1 $)^{[c]}(17)$ \\
\hline$(\mathrm{GlcNAc})_{6}(6)$ & AMB linker (12) & NodMI.R7A $\Delta O Z-V(M e, C 18: 1)$ (18) \\
\hline
\end{tabular}

\section{Nod factors ${ }^{[b]}$}

NodMI.R7A $\triangle$ nolOnodZ-V(Me,C18:0) (19) NodMI.R7A $\Delta$ nolOnodZ-V(Me,C16:0) (20) NodMI.R7A $\Delta$ nolO-V(Me,C18:1,Fuc,Ac) (21) NodMI.R7A $\Delta$ nolO-V(Me,C18:0,Fuc,Ac) (22) NodMI.R7A $\Delta$ nodSnolO-V(C18:1,Fuc,Ac) (23) NodMI.R7A $\Delta$ nolLnolO-V(Me,C18:1,Fuc) (24)

\section{PGN compounds}

MurNAc (25)

GICNAC-MurNAc (26)

GIcNAc-MurNAc-A-iso-q (27)

A-e-K-a (C-terminal; 28)

A-e-K-a (N-terminal; 29)

GlcNAc-MurNAc-A-e-K-a (30)

[a] The compounds conjugated with the AMB linker are designated by an A next to the compound number, so GlcNAc-AMB becomes 1 A. [b] Nod factor nomenclature as suggested by Heidstra and Bisseling. ${ }^{[32]} \mathrm{Ml}$ indicates that it originated from $M$. loti; R7A has been included in this paper to indicate the strain and which nod genes have been knocked out. [c] Chemoenzymatically prepared Nod factor. [d] Cb: carbamoyl; Fuc: fucose; Me: methyl; wt: wild type. 


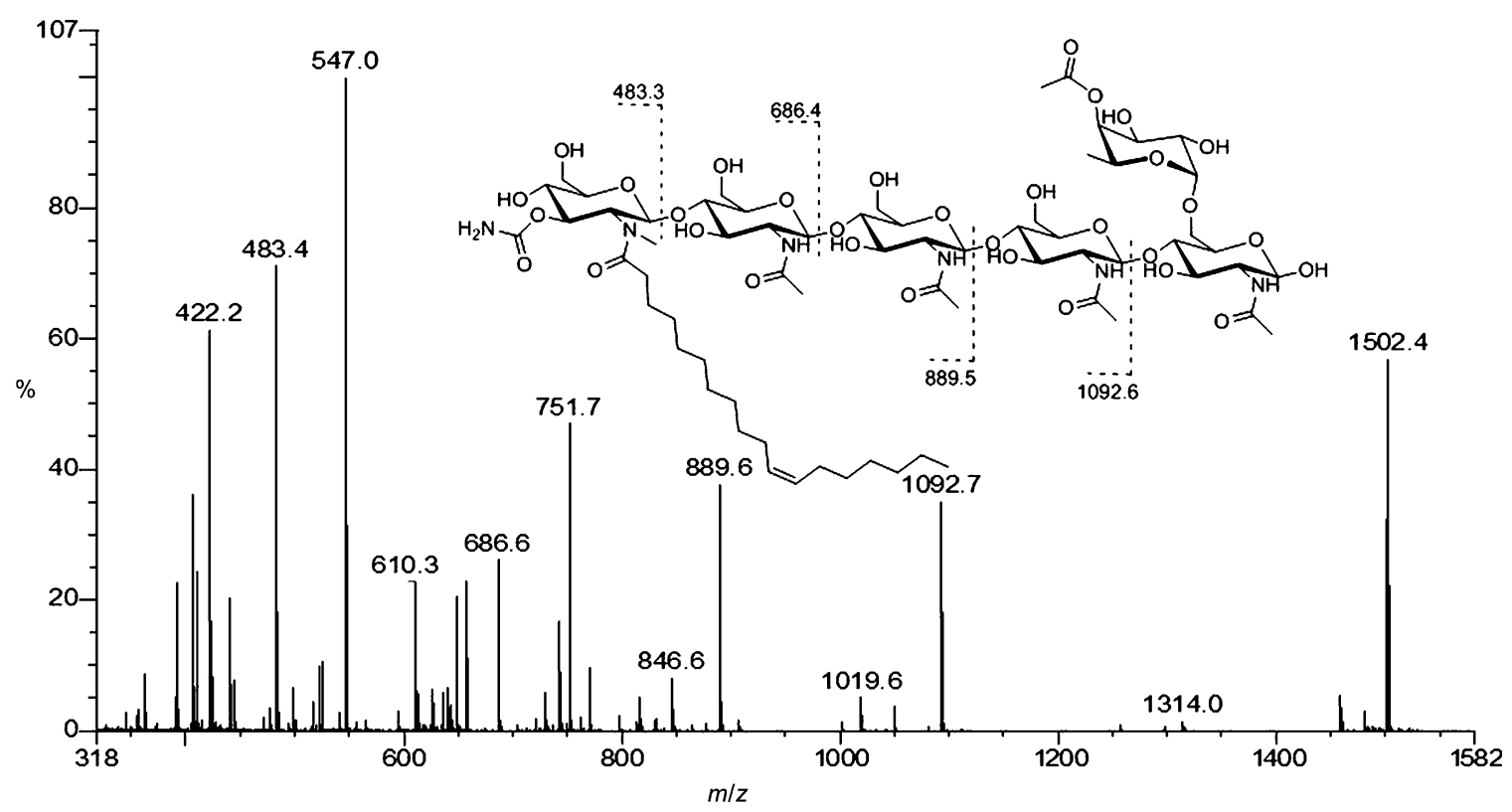

Figure 1. Mass spectrum of the major Nod factor product, NodMI.R7Awt-V(Me,Cb,18:1,FucAc), obtained from the unmodified M. loti R7A. The fragmentation patterns are easily recognized by the stepwise loss of a GlcNAc residue.

revealed the expected chemical traits at the reducing and nonreducing termini. The major Nod factor produced by $M$. loti R7A was the NodMI-V(Cb,Me,18:1,Fuc,Ac) (Figure 1), although minor Nod factor products with other lipid chains were also observed. Nod factors containing $C_{18: 0}$ and $C_{16: 0}$ chains were present, and these were isolated for immobilization on the array as well. The remainder of the Nod factors reported here were obtained from mutant strains of $M$. loti R7A defective in one or more genes required for complete Nod factor biosynthesis. ${ }^{[35]}$ The mutant strains produced different Nod factor yields, which might reflect an altered transmembrane transport efficiency ${ }^{[36]}$ or the need for a certain structural trait to be present for proper recognition by the other modifying enzymes. The identity of Nod factors was established by electrospray mass spectrometry (ESI-MS), and purity was assessed by HPLC (Figure 1 and Figure S3 in the Supporting Information). Table 1 provides an overview of the Nod factors obtained; the genotypes of the mutant strains involved are included.

\section{Lipochitin oligosaccharides and peptidoglycan synthesis}

Although some Nod factors were purified from extracts produced by using M. loti nod gene mutants, a chemoenzymatic synthesis approach was used to produce LCOs 8 and 17 (Table 1). The M. loti nodB gene was expressed in E. coli to enable purification of the resulting deacetylase. The enzyme product, NodB, catalyzes the deacetylation reaction, thereby making an amino group available at the nonreducing end of the chitin oligosaccharide. ${ }^{[37]}$ Having deacetylated the product, a biotin group (8) or a lipid chain (17) could be attached by using an $\mathrm{N}$-hydroxysuccinimide (NHS) ester as depicted in Scheme 2 .

A similar strategy for synthesizing a Nod factor, V(C18:0), was utilized by Huang and $\mathrm{Mei}^{[38]}$ by using an acid chloride for acylation. However, in our hands, the NHS approach was preferred because of its stability and water compatibility. The control compound, 11, was likewise synthesized by treating an NHS-activated stearic acid with glucosamine. Compound $\mathbf{8}$ was chosen for the array in order to view chitin-degrading activity if it was encountered. Isolated and synthesized Nod factors were reacted with an excess of AMB to provide glycoconjugates for array printing (Scheme 2).

The peptides included on the array were chosen based on the enzymatic activity of the protein involved in PGN synthesis and remodeling. ${ }^{[39]}$ The four amino acid sequences, which included two D-amino acids, constitute the linking residues connecting the GlcNAc-MurNAc chains in the bacterial cell wall PGN. ${ }^{[0]}$ The compounds were obtained through solid-phase peptide synthesis and were either designed with an aldehyde at the C-terminus (28) or N-terminus (29) to allow oxime formation with the UV-active AMB linker prior to immobilization on the array surface, or linked to GlcNAc-MurNAc (compound 30). These are depicted in Scheme 3.

\section{Array printing}

Every compound was printed in triplicate at four spot densities to avoid false positive readouts and to increase the likelihood of optimal conditions for proper binding (e.g., distance to ligand in cases of multiple binding sites). Lectin binding did indeed lead to more intense fluorescence readouts in the areas with high ligand density; this reflects the binding of more lectin molecules (Figure S6).

Carbohydrate linker conjugates were printed on NHS-activated glass slides ${ }^{[17]}$ in four different concentrations $(60,20,6.7$, and $2.2 \mu \mathrm{M}$ ) in triplicate, thus having different ligand densities which decrease in steps of $33 \%$ on the array surface. The identity of the glycoconjugates was verified by mass spectrometry 
<smiles>CC(=O)N[C@@H](C)C(=O)N[C@@H](CCC(=O)O)C(=O)N[C@@H](CCCCN)C(=O)N[C@@H](C)C(=O)NCC(=O)NCC=O</smiles><smiles>C[C@H](NC(=O)[C@H](CCCCN)NC(=O)[C@H](CCCCCN)NC(=O)[C@H](C)NC(=O)c1ccc(C=O)cc1)C(N)=O</smiles>

29: A-e-K-a (N-terminal)

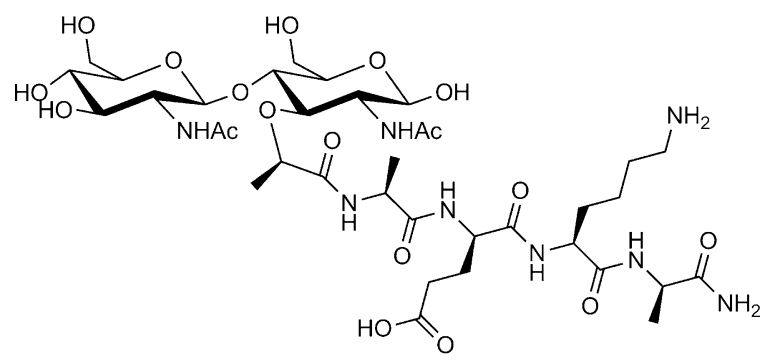

30: GIcNAc-MurNAc-A-e-K-a

Scheme 3. The PGN-related structures $\mathbf{2 8}, \mathbf{2 9}$, and $\mathbf{3 0}$ were designed to include an aldehyde to facilitate AMB linker conjugation as with the reducing carbohydrates. L-amino acids are designated by capital letters; D-amino acids are written in lower case.

prior to array printing. The quality of the printing was evaluated and then accepted after a "red scan" in which the geometrical placement and morphology was probed by a red laser immediately after printing to confirm spot appearance (Scheme 4).

\section{Verification of immobilized ligands}

Solanum tuberosum lectin (STL) was used to verify the presence of GlcNAc-containing carbohydrates on the array, whereas sera from humans were acquired to visualize GlcNAc-containing peptidoglycans, as demonstrated previously. ${ }^{[17]}$

To detect protein binding to the array ligands, STL was biotinylated, and streptavidin was used as secondary binder containing either a Cyanine3 (Cy3) or an Alexa label. STL is a dimeric protein with four carbohydrate binding sites. ${ }^{[41]}$ The $K_{d}$ values of STL binding to the unconjugated chitin oligomers and NodMI-V(Cb,Me,18:1,FucAc; 10) in solution were obtained by thermophoresis for comparison (Table 2).

The data obtained from the solution binding studies corresponded well qualitatively with the on-chip results from the glycan microarray. STL binds $\beta$ - $p$ GlcNAc glycosides; hence in chitin oligomers, the reducing end GICNAc would not be rec-

\begin{tabular}{|lrc|}
\hline \multicolumn{3}{|l|}{ Table 2. STL binding constants determined by thermophoresis. } \\
\hline Ligands & $K_{\mathrm{d}}[\mathrm{nm}]$ & Standard deviation \\
\hline GlcNAc & no binding & - \\
chitobiose & 115488 & 9148 \\
chitotriose & 5565 & 1150 \\
chitotetraose & 976 & 67 \\
chitopentaose & 731 & 218 \\
chitohexaose & 504 & 73 \\
chitooctaose & 685 & 64 \\
NodMI- $\mathrm{V}(\mathrm{Cb}, \mathrm{Me}, 18: 1, \mathrm{FucAc})$ & 1422 & 554 \\
\hline
\end{tabular}

ognized. In solution, the chitin tetramer is required for full recognition. Interestingly, this correlates well with the results from on-chip binding, where the glycans are covalently linked through an oxime linkage. The oxime linkage is in a dynamic equilibrium between the open-chain form and the ring-closed form, existing primarily as the $\beta$-glycoside. STL specificity towards GIcNAc oligosaccharides was further demonstrated by a competition experiment with $\mathrm{N}$-pentaacetyl chitopentaose as outlined in Figure S6.

Studies have indeed shown that the GlcNAc monomer cannot inhibit the agglutinating activity of STL, whereas chitobiose has only a weak ability to do so. ${ }^{[42]}$ As previously mentioned, the linked carbohydrate exists in a dynamic equilibrium between the open and closed forms, whereas only the closed form is expected to be recognized by proteins. However, previous work performed using a surface plasmon resonance (SPR) technique revealed that, despite the availability of the closed (pyranose) form of GlcNAc, wheat germ agglutinin (WGA) did not recognize the LacNAc at all. ${ }^{[36]}$ This result was contrary to ECA binding, which requires the entire disaccharide for recognition. In this case, the dissociation rate was higher and the association rate lower compared to the entirely ring-closed form, reflecting unstable binding due to the dynamic nature of the oxime coupling. ${ }^{[36]}$ WGA was tested on the array (Figure $2 \mathrm{C}$ ) and yielded an identical pattern to STL. Therefore, for these particular lectins, the first GlcNAc residue should not be considered as a part of the recognized structure, and two or more ring-closed GICNAc residues must be available for proper binding. However, this notion does not account for all GlcNAc-recognizing lectins, as WGA did bind chitotriose (3) on the array (Figure 2A).

It is likely that the chitin backbone is the primary part of the Nod factors that was recognized by the lectins we examined. Like STL, WGA (Figure 2C) recognized all Nod factors. However, looking at compound 22 (NodMI.R7A $\triangle$ nolO-V(Me, 18:0,FucAc)) and 18 (NodMI.R7A $\Delta$ nolOnodZ-V(Me,18:1)), there seems to be a difference in lectin binding affinities. This difference is even more apparent when looking at WGA and DSL. These two lectins only recognized about half of the Nod factors on the array, and WGA did not bind to compound 21 (NodMI.R7A $\triangle$ nolO$\mathrm{V}(\mathrm{Me}, 18: 1, \mathrm{FucAc}))$, unlike the rest of the lectins. One possibility is that the accessibility of the backbone determines the observed binding or lack thereof. However, if this was the only criterion, one would expect the binding patterns to be more 


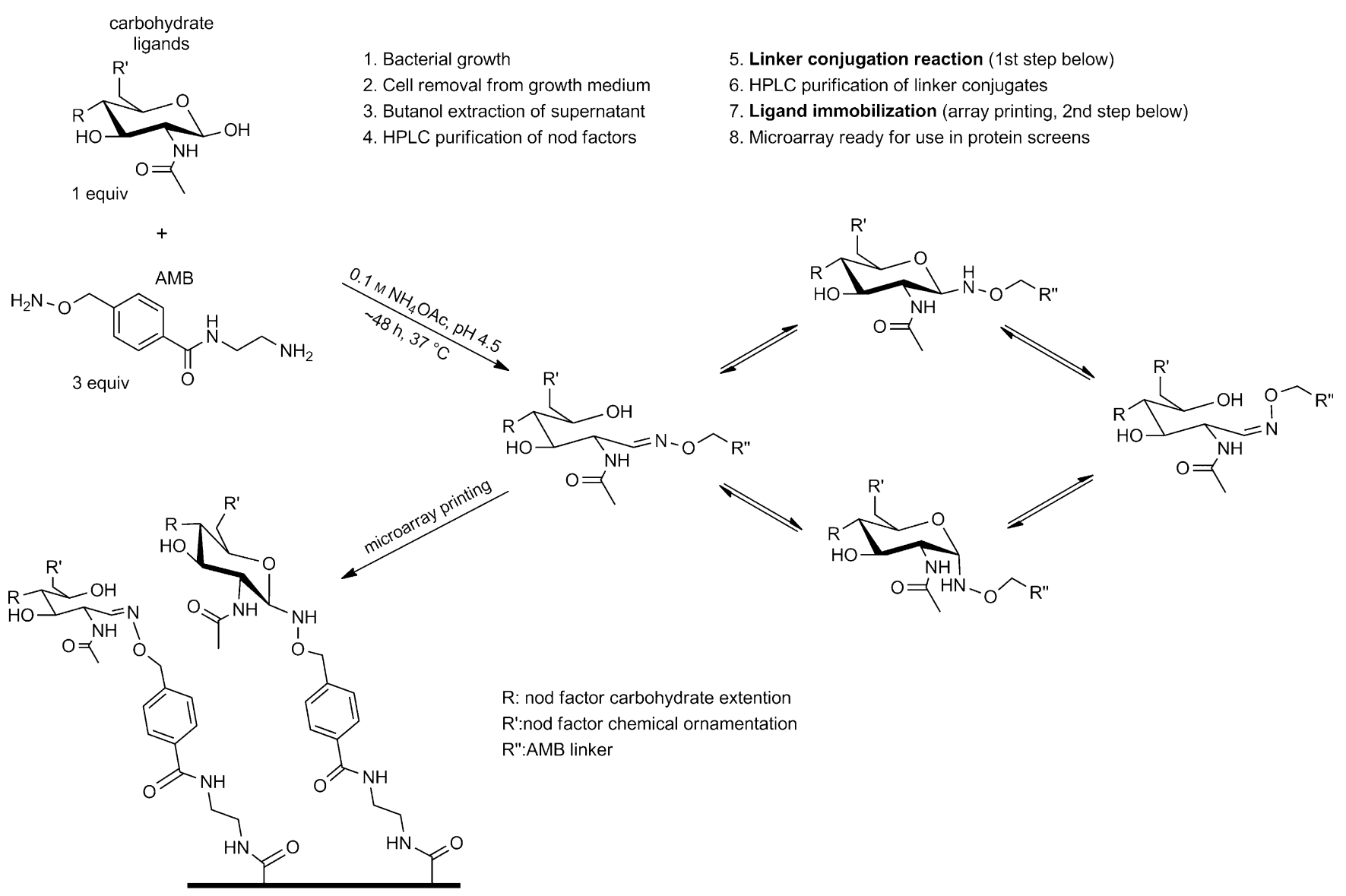

Scheme 4. Carbohydrate AMB linker conjugation. Nod factors were obtained through several steps of bacterial growth and compound extraction (see structure in Scheme 1). The reaction with AMB linker leads to the corresponding oxime, which exists in a dynamic equilibrium between open and closed forms. The linker conjugates were then printed on slides to generate the microarray glycochips.

similar. Thus, the ornamentation of Nod factors could play an important role in recognition.

For visualization of the PGN-related structures that did not bind to any lectins on the slide (25-30), we used anti humanIgG serum antibodies, as they contain a broad repertoire of anti-glycan reactivities, including against peptidoglycans. ${ }^{[17]} \mathrm{An}$ tibodies binding to the ligands were then visualized by adding fluorescently labeled goat anti-human IgG as the secondary binder. IgG is predominantly involved in the adaptive immune system but also recognizes various pathogenic bacteria and fungi. Sera from seven individuals were examined, and each sera exhibited slightly different readouts (Figure S9). These small differences were likely due to differences in pathogen exposure of the individuals but, taken together, they covered the PGN-related structures on the array, thereby confirming the presence of the PGN structures. An interesting observation was the recognition of compounds $\mathbf{2 7}$ and $\mathbf{3 0}$ in several of the tested sera samples. Compound 27, referred to in the literature as GIcNAc-MurNAc dipeptide (GMDP), ${ }^{[43]}$ has been reported to exhibit immunomodulatory properties.

This observation suggests that recognition might require the chitin moiety as well as certain chemical features provided by the Nod factors. Antibody binding to other carbohydrates on the array $(\mathbf{2}, \mathbf{3}, \mathbf{5}, \mathbf{6}, \mathbf{2 6}$, and $\mathbf{2 7})$ has been previously confirmed in similar array setups. ${ }^{[44]}$

\section{P60 autolysin on chip}

Binding of the lectins and the serum antibodies verified the presence of ligands on the array surface and proved that they were accessible. Only the mono- to trisaccharides 1-3 could not be visualized when using these proteins. The functionality of the array was subsequently tested with a LysM domain protein. P60 is an autolysin essential for the virulence of the human pathogen Listeria monocytogenes. ${ }^{[45]}$ The protein consists of two LysM domains, an SH3 domain, and a catalytic domain, which cleaves the peptide sequence connecting the GlcNAc-MurNAc chains in PGN. ${ }^{[45]}$ Cleavage is predicted to occur between D-iGlu, that is, at the side-chain amide bond, and mDAP in the sequence MurNAc-L-Ala-D-iGlu-mDAP-D-AlaD-Ala. For this study, p60 was expressed in E. coli and biotinylated upon purification. The array readout (Figure 3 ) showed binding of p60 to the longer chitin oligosaccharides and to some of the Nod factors but not to the peptidoglycans (2530) present on the array. Recent studies have indeed proven the ability of a plant receptor, CERK1, to bind a tetrameric chitin molecule through direct hydrogen bond interactions 


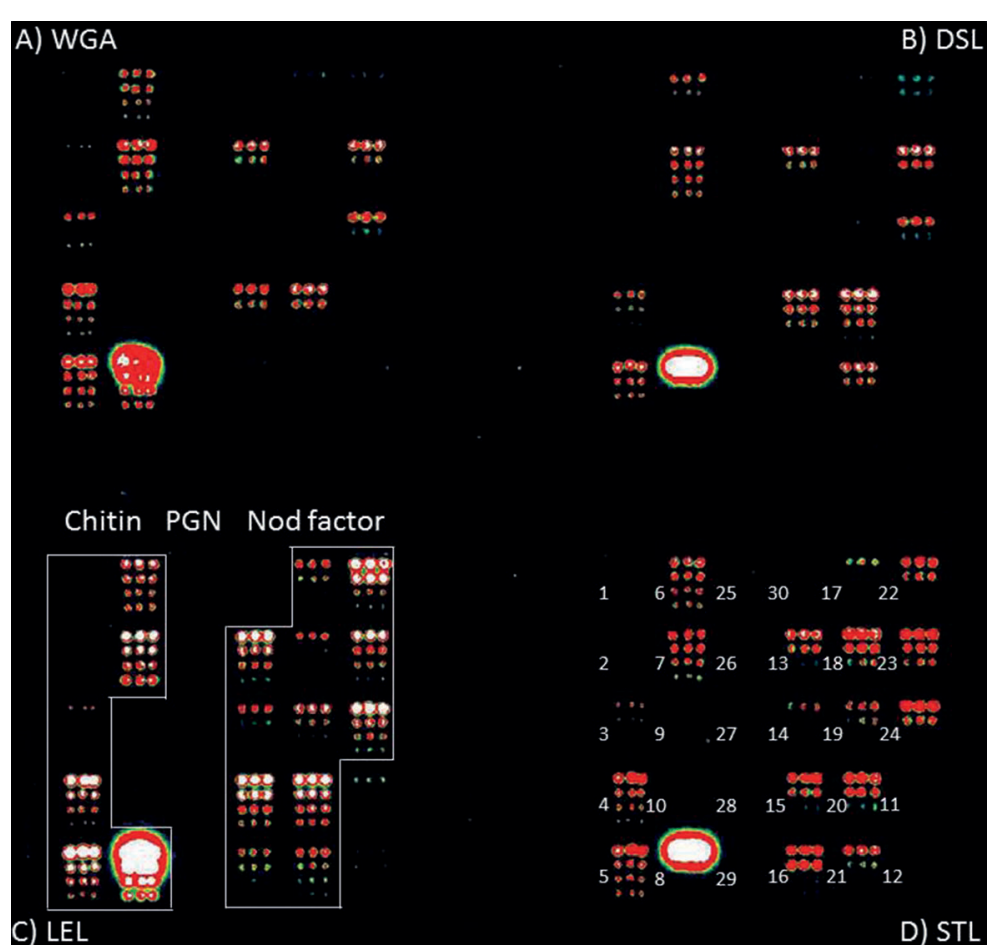

Figure 2. Lectin binding on array. A) WGA; B) DSL; C) LEL; D) STL. All four lectins are known to recognize GICNAc. The chitin oligomers (1-8) and Nod factor variants (13-24) are indicated on the LEL readout in the lower left corner, and the compound numbers are given in the lower right array readout. Compounds 11 and 12 were reference molecules. Each compound was spotted in three replicates at four concentrations to give a density range.
Based on the predicted cleavage site of p60, binding to peptidoglycans (25-30) would be expected. However, such an interaction between peptide and the p60 catalytic domain is likely to be transient and thus not visible in the present setup. Instead, it is possible that p60 was associated with the PGN GlcNAc-MurNAc chains through its LysM domains, thus bringing it into the vicinity of the peptide ligands to which its activity is to be exerted. However, binding was not observed for compounds 26, 27, and 30, which contain the GlcNAc-MurNAc moiety, but the chain length could be of critical importance to binding. Thermophoresis and isothermal calorimetry experiments also indicated an absence of binding to the peptidoglycans and GICNAc-MurNAc moietycontaining compounds (data not shown). Longer repeats of GlcNAc-MurNAc would be highly relevant to include on the array. This would allow comparison to the chitin oligosaccharide fragments, which are highly similar with regard to structure. However, tighter binding to GICNAc-MurNAc repeats may be expected, as these carbohydrates, in this case, must be considered the natural ligand. Unfortunately, GIcNAc-MurNAc oligosaccharides are very difficult to obtain. Purification of such well-defined PGN fragments and chemical synthesis have proven difficult and tedious, although great efforts have been made and impressively resulted in highly complex PGN-related structures. ${ }^{[46]}$

Interestingly, selective and differential binding to and van der Waals interactions with at least three of the GlcNAc units to a shallow groove on its LysM domain surface. ${ }^{[12]}$ Assuming that the presently observed LysM-chitin binding events take place in a similar fashion, it would be expected that longer chitin oligosaccharides would lead to higher affinity, as this would allow further contributions to the interaction.
Nod factors was observed for p60. This suggests that this enzyme exhibits a binding specificity that is dependent upon the structure of the lipid chain and the additional ornamentation. The possibility of a combined effect of these to determine the binding specificity cannot be excluded. Such a combination might influence the accessibility of the chitin backbone, which might be the primary cause of the interaction.
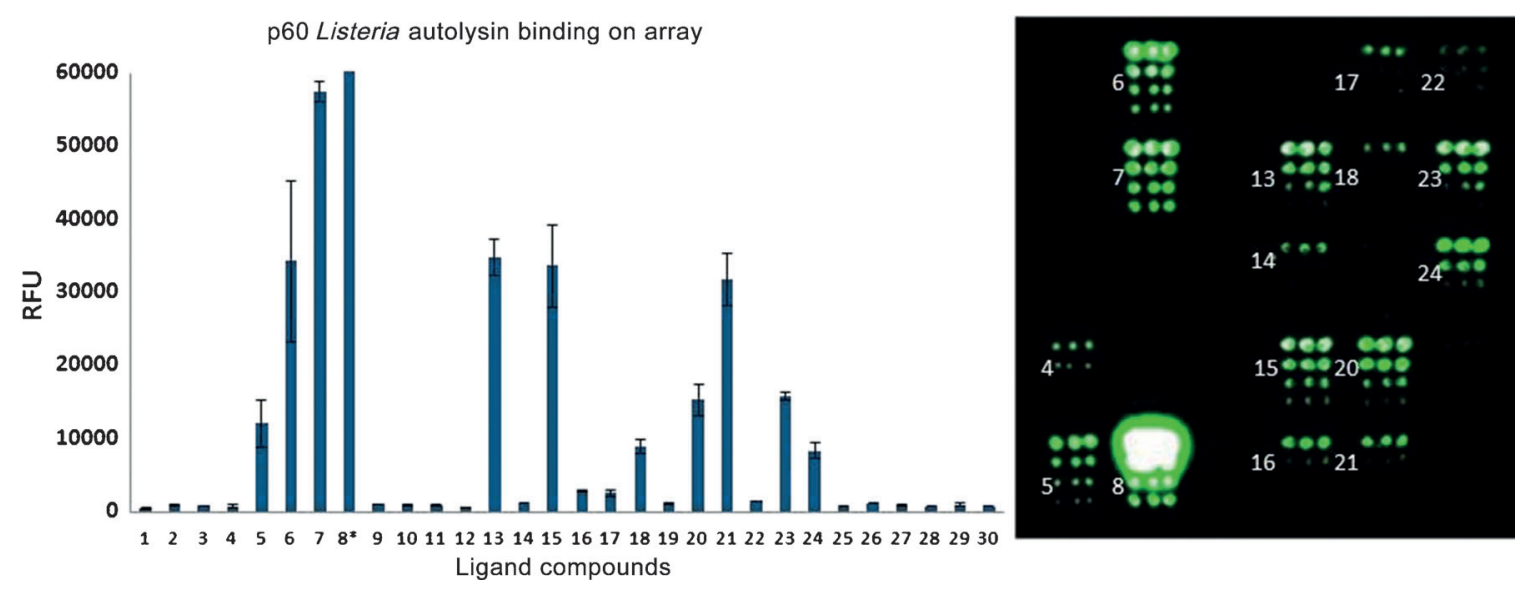

Ligand compounds

Figure 3. P60 binding to chitin oligosaccharides and Nod factors. Ligand compounds are positioned in numerical order starting with compounds 1-6 on the top row. One compound is represented by 12 spots, with four concentrations in three replicates. Compound details are listed in Table 1 . The bright spot at the bottom, second from the left, represents the biotinylated chitotetraose designed to detect chitin degrading activity by the disappearance of the signal. 


\section{Conclusions}

A glycan microarray containing 30 ligands was assembled through solid-phase peptide synthesis, chemoenzymatic synthesis, and compound isolation from M.loti R7A mutant strains, as well as highly chemoselective reactions with a bifunctional linker. The successful assembly was confirmed by lectin binding, as well as antibody recognition from human sera. The first study with these carbohydrate linker conjugates in an array setup involved binding of LysM domain-containing proteins. Application of the array was demonstrated by using the bacterial p60 autolysin, which surprisingly binds Nod factor variants, most likely through GIcNAc recognition. Our results demonstrate the application of novel bifunctional chemoselective aminooxy reagents without the need for transient carbohydrate protecting groups in an array setup to assess binding of LysM domain-containing protein.

\section{Experimental Section}

HPLC and mass spectrometry: Preparative HPLC and analytical HPLC-MS was performed on a Dionex Ultimate 3000 HPLC with Chromeleon 6.80SP3 software by using columns from FeF Chemicals $A / S(C-18,250 \times 21.2 \mathrm{~mm}, 5 \mu \mathrm{m}, 300 \AA)$ and Phenomenex (Gemini C-18, $50 \times 4.60 \mathrm{~mm}, 3 \mu \mathrm{m}, 110 \AA$ ), respectively. Purification of glycoconjugates was carried out by using a Waters HPLC system with a Dionex Acclaim Mixed-Mode HILIC-1 $150 \times 5 \mathrm{~mm}, 5 \mu \mathrm{m}$, $120 \AA$. Elution conditions were as follows: preparative HPLC for Nod factor purification; $10 \mathrm{~mL} \mathrm{~min}{ }^{-1}$ linear gradient flow of $B$ $\left(\mathrm{CH}_{3} \mathrm{CN}\right)$ in $\mathrm{A}\left(\mathrm{H}_{2} \mathrm{O}\right)$ over $35 \mathrm{~min}$. Analytical HPLC-MS for structure confirmation of Nod factors and glycoconjugates; $1.0 \mathrm{~mL} \mathrm{~min}^{-1}$ linear gradient flow of $\mathrm{B}\left(\mathrm{CH}_{3} \mathrm{CN}, 0.1 \%\right.$ formic acid $)$ in $\mathrm{A}\left(\mathrm{H}_{2} \mathrm{O}, 0.1 \%\right.$ formic acid) over $10 \mathrm{~min}$. HPLC on analytical HILIC column for glycoconjugate purification; $1.0 \mathrm{~mL} \mathrm{~min}{ }^{-1}$ linear gradient flow of $D$ $\left(\mathrm{CH}_{3} \mathrm{CN} / \mathrm{NH}_{4} \mathrm{OAc} 9: 1, \mathrm{v} / \mathrm{v}, 100 \mathrm{~mm}, \mathrm{pH} 5.8\right)$ in $\mathrm{C}\left(\mathrm{NH}_{4} \mathrm{OAc} 10 \mathrm{~mm}\right.$, $\mathrm{pH}$ 5.8) over $15 \mathrm{~min}$. The Dionex MSQ Plus mass spectrometer was set to a cone voltage of $70 \mathrm{~V}$ in electrospray ionization positive mode.

Commercially available carbohydrates: GICNACMurNAc was purchased from Toronto Research Chemical, Inc., GlcNAcMurNAc-LAla-D-iso-GIn from CalBioChem, MurNAc from Carbosynth, maltotetrose from Dextra Laboratories, Ltd., and chitin oligosaccharides and cellotetraose from Seikagaku Biobusiness Corporation.

NodB expression and purification: Primers were designed to amplify the M. loti R7A nodB gene. Both primers contained ligationindependent cloning (LIC) overhang sequences, and the forward primer also contained a ribosome binding site and tobacco etch virus (TEV) protease cleavage site. The nodB PCR product was inserted into the pET-30 Ek/LIC vector and transformed into E. coli BL21 (DE3) to enable His tag purification of the expressed NodB protein.

Nod factor isolation: Plasmid pMP2112 ${ }^{[47]}$ containing nodD from Rhizobium leguminosarum was transferred to $M$. loti strains to allow induction of nod gene expression by using naringenin. ${ }^{\left[{ }^{[8]}\right.}$ The Nod factors were then extracted from the growth medium by using $1 / 4$ volume butanol, followed by reversed-phase preparative HPLC as previously reported. ${ }^{[49]}$ Products were lyophilized prior to conjugation with the AMB linker as described by Cló, Blixt, and Jensen. ${ }^{[29]}$
Ligand synthesis: Peptides were synthesized by solid-phase peptide synthesis (SPPS). Coupling of amino acids was carried out with microwave-assisted SPPS on an automated peptide synthesizer (SyroWave, Biotage) with 9-fluorenylmethyloxycarbonyl (Fmoc) for protection of $N^{\alpha}$-amino groups. TentaGel $S$ Amide resin (0.27 $\mathrm{mmol} \mathrm{g}^{-1}$, Rapp Polymere $\mathrm{GmbH}$ ) was used to assemble peptide 28, whereas TentaGel S Rink Amide resin $\left(0.24 \mathrm{mmolg}^{-1}\right.$, Rapp Polymere $\mathrm{GmbH}$ ) was used for peptides 29 and 30 . Side-chain-protecting groups were tert-butyl on Glu and tert-butyloxycarbonyl on Lys. $N^{\alpha}$-Fmoc amino acids (5.0 equiv) were coupled by using $N$ [(1H-benzotriazol-1-yl)(dimethylamino)methylene]- $N$-methylmethanaminium-hexafluorophosphate- $N$-oxide (HBTU; 4.75 equiv), 1-hydroxy-7-azabenzotriazole (HOAt; 5 equiv) and $\mathrm{N}, \mathrm{N}$-diisopropylethylamine (DIEA; 9.75 equiv) as coupling reagents in DMF for $2 \times$ $10 \mathrm{~min}$ at $75^{\circ} \mathrm{C}$. $N^{\alpha}$-Fmoc deprotections were performed with piperidine/DMF (2:5) for 3 min, followed by $2 \times$ piperidine/DMF (1:4) for $15 \mathrm{~min}$. Between couplings and deprotections, the resin was washed with $3 \times N M P, D C M$, and then $3 \times$ NMP. The peptides were released from the solid support by treatment with trifluoroacetic acid (TFA)/ $\mathrm{H}_{2} \mathrm{O}(95: 5)$ for $2 \mathrm{~h}$. The TFA solutions were concentrated by nitrogen flow, and the compounds were precipitated with diethyl ether to yield the crude material. Amino acids, coupling reagents, DIEA, piperidine, DMF, and NMP were all obtained from Iris Biotech GmbH, Germany and Sigma-Aldrich, Denmark. The crude peptides were purified by RP-HPLC (on a Dionex Ultimate 3000 system) on a preparative C18 column (Phenomenex $110 \AA, 10 \mu \mathrm{m}$, C18 particles, $2.1 \times 200 \mathrm{~mm}$ ). The purity of the peptide was established by analytical HPLC, and identification was carried out by ESIMS (MSQ Plus Mass Spectrometer, Thermo).

For the preparation of compound $\mathbf{2 8}$, the TentaGel $\mathbf{S}$ Amide resin with a free amino group and no linker was placed in a reaction syringe. A solution containing o-PALdehyde ${ }^{[50]}(34.64 \mathrm{mg}, 0.2 \mathrm{mmol})$, HBTU $(73.96 \mathrm{mg}, 0.195 \mathrm{mmol})$, HOAt $(27.02 \mathrm{mg}, 0.2 \mathrm{mmol})$, and DIEA $(46.53 \mathrm{mg}, 0.36 \mathrm{mmol}$ ) was prepared in $2 \mathrm{~mL}$ DMF. This solution was added to the resin and left on a shaker overnight at room temperature. The resin was washed with $3 \times \mathrm{NMP}, 3 \times \mathrm{DCM}$, and $3 \times$ NMP and placed in a microwave vial. 2,2-Dimethoxyethylamine $(105.14 \mathrm{mg}, 1 \mathrm{mmol})$ and sodium cyanoborohydride $(62.8 \mathrm{mg}$, $1 \mathrm{mmol}$ ) were added to this, along with $\mathrm{MeOH}(3 \mathrm{~mL}$ ) containing $1 \%$ acetic acid. The reaction vial was then heated in a microwave instrument for $10 \mathrm{~min}$ at $60^{\circ} \mathrm{C}$. The resin was washed with $\mathrm{MeOH}$, and the reaction was repeated to ensure full incorporation. The resin was washed thoroughly with $3 \times \mathrm{NMP}, 3 \times \mathrm{DCM}, 3 \times \mathrm{NMP}$, and $3 \times D C M$ and placed in a microwave vial to which a solution of Fmoc-Gly (297.4 mg, $1 \mathrm{mmol}$ ) and DIC (63.1 mg, $0.5 \mathrm{mmol}$ ) in DCM/ DMF (10:1) was added. The reaction was heated in the microwave at $60^{\circ} \mathrm{C}$ for $10 \mathrm{~min}$. The resin was washed in DCM/DMF (10:1), and the reaction was repeated with fresh reagents. After washing with $3 \times N M P, 3 \times D C M$, and $3 \times N M P$, the remaining amino acids were attached under the conditions described above. The peptide was cleaved by TFA and then purified by HPLC according to the following procedure: solvent $A$, water containing $0.1 \%$ TFA; solvent $B$, $\mathrm{CH}_{3} \mathrm{CN}$ containing $0.1 \%$ TFA. Gradient elution (0-20 min: 5-50\%) was applied at a flow rate of $15 \mathrm{~mL} \mathrm{~min}^{-1}$. Calculated mass for the target compound: $\mathrm{C}_{23} \mathrm{H}_{39} \mathrm{~N}_{7} \mathrm{O}_{9} 557.3 \mathrm{Da}$. Masses found by ESI-MS: $\mathrm{m} / \mathrm{z} 558.2[\mathrm{M}+\mathrm{H}]^{+}$.

The tetrapeptide in $\mathbf{2 9}$ was synthesized according to the general procedure described above. It was then purified by preparative HPLC according to the following procedure: solvent $A$, water containing $0.1 \%$ TFA; solvent $\mathrm{B}, \mathrm{CH}_{3} \mathrm{CN}$ containing $0.1 \%$ TFA. Gradient elution (0-20 min: $5-60 \%$ ) was applied at a flow rate of $10 \mathrm{~mL} \mathrm{~min}^{-1}$. The $\mathrm{N}$-terminal modification was done directly on 
resin by adding a solution containing 4-(dimethoxymethyl)benzoic acid $(78.4 \mathrm{mg}, 0.4 \mathrm{mmol})$, HBTU $(147.9 \mathrm{mg}, 0.39 \mathrm{mmol}), \mathrm{HOAt}$ $(54.04 \mathrm{mg}, 0.4 \mathrm{mmol})$, and DIEA $(93.06 \mathrm{mg}, 0.72 \mathrm{mmol})$ in DMF $(4 \mathrm{~mL})$. This solution was added to the resin-bound peptide and left on a shaker for $2 \mathrm{~h}$ at room temperature. The resin was then washed as follows: $3 \times \mathrm{NMP}, 3 \times \mathrm{DCM}, 3 \times \mathrm{NMP}$, and $6 \times \mathrm{DCM}$, prior to TFA cleavage and subsequent HPLC purification according to the following procedure: solvent $A$, water containing $0.1 \%$ TFA; solvent $\mathrm{B}, \mathrm{CH}_{3} \mathrm{CN}$ containing $0.1 \%$ TFA. Gradient elution (0-25 min: 5-60\%) was applied at a flow rate of $10 \mathrm{~mL} \mathrm{~min}^{-1}$. Calculated mass for the target compound: $\mathrm{C}_{25} \mathrm{H}_{36} \mathrm{~N}_{6} \mathrm{O}_{8} 548.3 \mathrm{Da}$. Masses found by ESI-MS: $m / z 549.3[M+H]^{+}$.

The tetrapeptide in $\mathbf{3 0}$ was identical to that in $\mathbf{2 9}$ and was thus synthesized by the same approach. The peptide was cleaved from the resin, purified $(10 \mathrm{mg}, 0.024 \mathrm{mmol})$, and placed in a microwave vial. To this was added HBTU $(3.6 \mathrm{mg}, 0.0096 \mathrm{mmol}), \mathrm{HOAt}(1.4 \mathrm{mg}$, $0.0104 \mathrm{mmol})$, and GlcNAc-MurNAc $(5.16 \mathrm{mg}, 0.0104 \mathrm{mmol})$, dissolved in $1.5 \mathrm{~mL}$ DMF. The solution was basified by adding DIEA $(3.2 \mu \mathrm{L}, 0.0192 \mathrm{mmol})$. The reaction mixture was heated in the microwave at $75^{\circ} \mathrm{C}$ for $10 \mathrm{~min}$ with stirring. DMF was removed under vacuum, and the crude material was purified by HPLC with solvent A, water containing $0.1 \%$ TFA; solvent $\mathrm{B}$, MeOH containing $0.1 \%$ TFA. Gradient elution (0-20 min: $5-20 \%$ was applied at a flow rate of $10 \mathrm{~mL} \mathrm{~min}{ }^{-1}$. Calculated mass for the target compound: $\mathrm{C}_{36} \mathrm{H}_{62} \mathrm{~N}_{8} \mathrm{O}_{18}$ 894.4 Da. Masses found by ESI-MS: $\mathrm{m} / \mathrm{z} 895.1[\mathrm{M}+\mathrm{H}]^{+}$ and $448.2[\mathrm{M}+\mathrm{H}]^{2+}$.

A synthetic Nod factor, 17, was generated chemoenzymatically. Enzymatic deacetylation at the nonreducing terminal GIcNAc unit of $N$-pentaacetyl chitopentaose was catalyzed by NodB in $20 \mathrm{~mm}$ MOPS buffer, pH 7.2. Acylation of the resulting mono-deacetylated chitopentaose was carried out in $80 \% \mathrm{CH}_{3} \mathrm{CN}$ with an NHS-activated cis-vaccenic acid ( 6 equiv) under basic conditions (3.5 equiv $\mathrm{Et}_{3} \mathrm{~N}$ ) at $35^{\circ} \mathrm{C}$ for $16 \mathrm{~h}$. Purification of the target molecule, 17, was performed on a preparative HPLC, providing a $15 \%$ yield. The biotinylated $\mathrm{N}$-triacetyl chitotetraose, 8, was prepared under similar conditions except for the acylation step, which was carried out in $50 \% \mathrm{CH}_{3} \mathrm{CN}$ with NHS-biotin from CalBioChem. Stearinylated glucosamine 11 was prepared by treating the NHS-activated stearic acid (1.5 equiv) with glucosamine (1.5 equiv) in DMF and was purified by flash chromatography with an EtOAc/heptane gradient and $\mathrm{MeOH}$ to give a $31 \%$ yield.

Array assembly: Ligand-linker conjugates were prepared on a $0.5-5 \mu \mathrm{mol}$ scale by reacting 3 equiv $\mathrm{AMB}$ with the carbohydrates in either $\mathrm{CH}_{3} \mathrm{CN} / \mathrm{H}_{2} \mathrm{O}(1: 1)$ or $\mathrm{MeCN} / 100 \mathrm{~mm} \mathrm{NH}{ }_{4} \mathrm{OAc}$ buffer $\mathrm{pH} 4.5$ (1:1) for $2 \mathrm{~h}$ at $35^{\circ} \mathrm{C}$. Conjugation yields were in the range of approximately $20-50 \%$. Purification of the compounds was carried out on an Acclaim mixed-mode HILIC HPLC column from Dionex. Ligand-linker conjugates were then lyophilized and stored at $4{ }^{\circ} \mathrm{C}$ until printing on an array. All linker-conjugate structures were confirmed by MS under the conditions described above. MS data is available in Table S1. Printing was done according to the conditions previously reported by the Blixt lab. ${ }^{[51]}$ Surface-functionalized glass slides containing NHS-activated carboxyl groups (Nexterion $\mathrm{H}$ MPX-16; with 16 subarrays, divided by a teflon layer) was used with the BioRobotics MicroGrid II spotter. Print buffer contained $150 \mathrm{~mm}$ phosphate and $0.005 \%$ CHAPS, pH 8.5. Linker-conjugate concentrations were determined based on a UV standard curve. All compounds were printed in concentrations of $60,20,6.67$, and $2.22 \mu \mathrm{M}$, respectively, to vary the compound density on the surface. The slides were incubated for $60 \mathrm{~min}$ in a humidity chamber immediately after printing. To block excess unreacted NHS-esters, the glycan arrays were submerged in blocking buffer containing ethanolamine $(50 \mathrm{~mm})$ and borate $(50 \mathrm{~mm}), \mathrm{pH} 9.2$, for $30 \mathrm{~min}$ at room temperature.

Array experiments and data representation: Proteins were solubilized in PLI-P (buffer containing $0.5 \mathrm{M} \mathrm{NaCl}, 3 \mathrm{~mm} \mathrm{KCl}, 1.5 \mathrm{~mm}$ $\mathrm{KH}_{2} \mathrm{PO}_{4}, 6.5 \mathrm{~mm} \mathrm{Na} \mathrm{HPO}_{4}, 1 \%$ BSA, $1 \%$ Triton-X-100, pH 7.4) and submitted directly onto the array surface at $20 \mu \mathrm{L}$ per subarray. P60 $(0.8 \mu \mathrm{M})$, YkuD $(10 \mu \mathrm{M})$, and STL $(0.004 \mu \mathrm{M}$; Vector Labs) were incubated on array overnight at $4{ }^{\circ} \mathrm{C}$, followed by addition of the secondary dye, Streptavidin-Cy3 (Invitrogen). The entire slide was washed in PBS containing $0.05 \%$ Tween, followed by washing in PBS after each incubation step and drying by centrifugation. Sera (Asterand) were diluted 50 times in PLI-P buffer prior to incubation on the array. Visualization was achieved by adding goat antihuman IgG Alexa 488 (Invitrogen). Images of spots on arrays were retrieved by use of a ProScanArray HT microarray scanner (Perkin Elmer). Data acquisition and handling, such as readout intensity quantification, was performed by using the ProScanArray Express 4.0 software (PerkinElmer). For the data represented in bar diagrams, the bar values represent an average of the three spot readouts at the same concentration. The concentration of $20 \mu \mathrm{m}$ was chosen to be representative of the data, as the fluorescence intensity did not reach saturation and was thus within the dynamic range. Error bars represent variation based on these three replicate signal readouts.

Expression, purification, and labeling of the p60 protein: The gene encoding the p60 protein from Listeria monocyotenes was amplified by PCR from genomic DNA and cloned into the pET30 Ek/Lic vector from Novagen. The $5^{\prime}$-end of the gene encoding the first 26 amino acids (peptide signal) was removed. In order to obtain a catalytically inactive protein, the catalytic residue Cys396 was mutated to Ala by PCR mutagenesis. The resulting construct, pET30:P60mut, allows expression of the protein fused to a His tag and an Stag. A TEV protease site was introduced after the two tags. E. coli BL21 cells were used for expression. The protein was purified by three purification steps: first, immobilized metal affinity chromatography (IMAC), followed by TEV protease cleavage and a second IMAC step to get rid of the His and S tags, then size-exclusion chromatography. Prior to labeling, proteins were dialyzed against $50 \mathrm{~mm}$ phosphate buffer, $\mathrm{pH} 7.5$, and labeling was done following instructions from the SureLINK Chromophoric Biotin kit.

Microscale thermophoresis: The STL lectin was labeled by using the Monolith NT.115 Protein Labeling Kit BLUE (NanoTemper Technologies) to achieve a 1:1 molar ratio of labeled protein to dye. A titration series was prepared in which the concentration of the labeled proteins was kept constant at $50 \mathrm{~nm}$, and the concentration of the titrant was varied in thermophoresis buffer $(50 \mathrm{~mm}$ phosphate $\mathrm{pH} 7.5,0.4 \mathrm{M} \mathrm{NaCl}$, and $0.1 \%$ Tween-20). After incubation for $30 \mathrm{~min}, \mathrm{MST}$ measurements were performed at room temperature on a Monolith NT.115 instrument (NanoTemper Technologies). For each measurement, the laser was switched on for $30 \mathrm{~s}$ and off for $5 \mathrm{~s}$. Each experiment was repeated three times, and average $K_{\mathrm{d}}$ values were calculated after fitting the data with GraphPad Prism software.

\section{Acknowledgements}

This work was supported by the Danish National Research Foundation grant no. DNRF79 (to K.J.J. and J.S.) and EC FP7 BioM no. 259869 (to O.B.). 
Keywords: chemoenzymatic synthesis - glycan microarrays glycoconjugates $\cdot$ lectins $\cdot$ Nod factors

[1] C. R. Bertozzi, L. L. Kiessling, Science 2001, 291, 2357-2364.

[2] D. P. Gamblin, E. M. Scanlan, B. G. Davis, Chem. Rev. 2009, 109, 131-163.

[3] P. R. Crocker, T. Feizi, Curr. Opin. Struct. Biol. 1996, 6, 679-691.

[4] A. Helenius, M. Aebi, Annu. Rev. Biochem. 2004, 73, 1019-1049.

[5] H. P. Spaink, Annu. Rev. Microbiol. 2000, 54, 257-288.

[6] S. Radutoiu, L. H. Madsen, E. B. Madsen, H. H. Felle, Y. Umehara, M. Grùnlund, S. Sato, Y. Nakamura, S. Tabata, N. Sandal, J. Stougaard Nature 2003, 425, 585-592.

[7] A. Steen, G. Buist, K. J. Leenhouts, M. El Khattabi, F. Grijpstra, A. L. Zomer, G. Venema, O. P. Kuipers, J. Kok, J. Biol. Chem. 2003, 278, $23874-$ 23881.

[8] T. Ohnuma, S. Onaga, K. Murata, T. Taira, E. Katoh, J. Biol. Chem. 2008, 283, 5178-5187.

[9] A. Bateman, M. Bycroft, J. Mol. Biol. 2000, 299, 1113-1119.

[10] J. Bielnicki, Y. Devedjiev, U. Derewenda, Z. Dauter, A. Joachimiak, Z. S Derewenda, Proteins Struct. Funct. Bioinf. 2006, 62, 144-151.

[11] L. Mulder, B. Lefebvre, J. Cullimore, A. Imberty, Glycobiology 2006, 16 $801-809$.

[12] T. Liu, Z. Liu, C. Song, Y. Hui, Z. Han, J. She, F. Fan, J. Wang, C. Jin, J. Chang, J.-M. Zhou, J. Chai, Science 2012, 336, 1160-1164.

[13] A. Sánchez-Vallet, R. Saleem-Batcha, A. Kombrink, G. Hansen, D.-J. Valkenburg, B. P. H. J. Thomma, J. R. Mesters, eLife 2013, 2, e00790.

[14] A. Broghammer, L. Krusell, M. Blaise, J. Sauer, J. T. Sullivan, N. Maolanon, M. Vinther, A. Lorentzen, E. B. Madsen, K. J. Jensen, P. Roepstorff, S. Thirup, C. W. Ronson, M. B. Thygesen, J. Stougaard, Proc. Natl. Acad. Sci. USA 2012, 109, 13859-13864.

[15] R. D. Finn, J. Mistry, J. Tate, P. Coggill, A. Heger, J. E. Pollington, O. L. Gavin, P. Gunasekaran, G. Ceric, K. Forslund, L. Holm, E. L. Sonnhammer S. R. Eddy, A. Bateman, Nucleic Acids Res. 2010, 38, D211 -D222.

[16] a) N. Laurent, J. Voglmeir, S. L. Flitsch, Chem. Commun. 2008, $4400-$ 4412; b) K. Larsen, M. Thygesen, F. Guillaumie, W. Willats, K. J. Jensen Carbohydr. Res. 2006, 341, 1209-1234; c) J. C. Paulson, O. Blixt, B. E. Collins, Nat. Chem. Biol. 2006, 2, 238-248; d) S. Park, M.-R. Lee, I. Shin Chem. Commun. 2008, 4389; e) T. Horlacher, P. H. Seeberger, Chem. Soc Rev. 2008, 37, 1414-1422; f) S. Park, J. C. Gildersleeve, O. Blixt, I. Shin, Chem. Soc. Rev. 2013, 42, 4310-4326.

[17] O. Blixt, S. Head, T. Mondala, C. Scanlan, M. E. Huflejt, R. Alvarez, M. C. Bryan, F. Fazio, D. Calarese, J. Stevens, N. Razi, D. J. Stevens, J. J. Skehel, I. van Die, D. R. Burton, I. A. Wilson, R. Cummings, N. Bovin, C.-H. Wong J. C. Paulson, Proc. Natl. Acad. Sci. USA 2004, 101, 17033-17038.

[18] S. Serna, J. Etxebarria, N. Ruiz, M. Martin-Lomas, N.-C. Reichardt, Chem. Eur. J. 2010, 16, 13163-13175.

[19] S.-H. Chang, J.-L. Han, S. Y. Tseng, H.-Y. Lee, C.-W. Lin, Y.-C. Lin, W.-Y. Jeng, A. H.-J. Wang, C.-Y- Wu, C.-H. Wong, J. Am. Chem. Soc. 2010, 132, $13371-13380$

[20] a) P.-H. Liang, S.-K. Wang, C.-H. Wong, J. Am. Chem. Soc. 2007, 129, 11177-11184; b) S. Park, I. Shin, Org. Lett. 2007, 9, 1675-1678.

[21] a) M.-R. Lee, I. Shin, Org. Lett. 2005, 7, 4269-4272; b) Z.-I. Zhi, A. K. Powell, J. E. Turnbull, Anal. Chem. 2006, 78, 4786-4793.

[22] I. Shin, S. Park, M. R. Lee, Chem. Eur. J. 2005, 11, 2894-2901.

[23] O. Bohorov, H. Andersson-Sand, J. Hoffmann, O. Blixt, Glycobiology 2006, 16, 21C-27C

[24] a) A. Dirksen, S. Dirksen, T. M. Hackeng, P. E. Dawson, J. Am. Chem. Soc 2006, 128, 15602-15603; b) J. Kalia, R. T. Raines, Angew. Chem. 2008, 120, 7633-7636; Angew. Chem. Int. Ed. 2008, 47, 7523-7526.
[25] F. Peri, P. Dumy, M. Mutter, Tetrahedron 1998, 54, 12269-12278.

[26] S. Park, M.-R. Lee, I. Shin, Bioconjugate Chem. 2009, 20, 155-162.

[27] Y. Liu, T. Feizi, M. Campanerorhodes, R. Childs, Y. Zhang, B. Mulloy, P. Evans, H. Osborn, D. Otto, P. Crocker, Chem. Biol. 2007, 14, 847-859.

[28] M. B. Thygesen, J. Sauer, K. J. Jensen, Chem. Eur. J. 2009, 15, 1649-1660.

[29] E. Cló, O. Blixt, K. J. Jensen, Eur. J. Org. Chem. 2010, 540-554.

[30] Y. Hatanaka, U. Kempin, P. Jong-Jip, J. Org. Chem. 2000, 65, 5639-5643.

[31] C. Jiménez-Castells, B. G. de La Torre, D. Andreu, R. Gutiérrez-Gallego, Glycoconjugate J. 2008, 25, 879-887.

[32] R. Heidstra, T. Bisseling, New Phytol. 1996, 133, 25-43.

[33] J.-F. Arrighi, A. Barre, B. Ben Amor, A. Bersoult, L. C. Soriano, R. Mirabella, F. de Carvalho-Niebel, E.-P. Journet, M. Gherardi, T. Huguet, R. Geurts, J. Denarie, P. Rouge, C. Gough, Plant Physiol. 2006, 142, 265-279.

[34] A. Miya, P. Albert, T. Shinya, Y. Desaki, K. Ichimura, K. Shirasu, Y. Narusaka, N. Kawakami, H. Kaku, N. Shibuya, Proc. Natl. Acad. Sci. USA 2007, 104, 19613-19618.

[35] J. T. Sullivan, J. R. Trzebiatowski, R. W. Cruickshank, J. Gouzy, S. D. Brown, R. M. Elliot, D. J. Fleetwood, N. G. McCallum, U. Rossbach, G. S. Stuart, J. E. Weaver, R. J. Webby, F. J. de Bruijn, C. W. Ronson, J. Bacteriol. 2002, 184, 3086- 3095.

[36] S. Jabbouri, B. Relic, M. Hanin, P. Kamalaprija, U. Burger, D. Promé, J. C. Promé, W. J. Broughton, J. Biol. Chem. 1998, 273, 12047-12055.

[37] M. John, H. Röhrig, J. Schmidt, U. Wieneke, J. Schell, Proc. Natl. Acad. Sci. USA 1993, 90, 625-629.

[38] G.-L. Huang, X.-Y. Mei, J. Enzyme Inhib. Med. Chem. 2007, 22, 247-249.

[39] H. Bierne, P. Cossart, Microbiol. Mol. Biol. Rev. 2007, 71, 377-397.

[40] S. O. Meroueh, K. Z. Bencze, D. Hesek, M. Lee, J. F. Fisher, T. L. Stemmler, S. Mobashery, Proc. Natl. Acad. Sci. USA 2006, 103, 4404-4409.

[41] E. J. M. Van Damme, A. Barre, P. Rouge, W. J. Peumans, Plant J. 2004, 37 , 34-45.

[42] A. K. Allen, A. Neuberger, Biochem. J. 1973, 135, 307-314.

[43] E. Meshcheryakova, S. Guryanova, E. Makarov, L. Alekseeva, T. Andrononva, V. Ivanov, Int. Immunopharmacol. 2001, 1, 1857-1865.

[44] M. E. Huflejt, M. Vuskovic, D. Vasiliu, H. Xu, P. Obukhova, N. Shilova, A. Tuzikov, O. Galanina, B. Arun, K. Lu, N. Bovin, Mol. Immunol. 2009, 46, 3037-3049.

[45] L. L. Lenz, S. Mohammadi, A. Geissler, D. A. Portnoy, Proc. Natl. Acad. Sci. USA 2003, 100, 12432-12437.

[46] D. Hesek, M. Lee, K.-i. Morio, S. Mobashery, J. Org. Chem. 2004, 69, 2137-2146.

[47] H. P. Spaink, R. J. H. Okker, C. A. Wijffelman, T. Tak, L. Goosen-De Roo, E. Pees, A. A. N. van Brussel, B. J. J. Lugtenberg, J. Bacteriol. 1989, 171, 4045-4053.

[48] I. M. López-Lara, J. D. J. van den Berg, J. E. Thomas-Oates, J. Glushka B. J. J. Lugtenberg, H. P. Spaink, Mol. Microbiol. 1995, 15, 627-638.

[49] A. S. Bek, J. Sauer, M. B. Thygesen, J. Ø. Duus, B. O. Petersen, S. Thirup, E. James, K. J. Jensen, J. Stougaard, S. Radutoiu, Mol. Plant-Microbe Interact. 2010, 23, 58-66.

[50] U. Boas, J. Brask, J. B. Christensen, K. J. Jensen, J. Comb. Chem. 2002, 4 $223-228$.

[51] O. Blixt, E. Cló, A. S. Nudelman, K. K. Sørensen, T. Clausen, H. H. Wandall, P. O. Livingston, H. Clausen, K. J. Jensen, J. Proteome Res. 2010, 9, $5250-$ 5261

Received: August 9, 2013

Published online on II, 0000 


\section{FULL PAPERS}

Hold still! Complex lipochitin oligosaccharides were immobilized by oxime linkages to form a glycan microarray to evaluate binding of proteins containing LysM domains. Array functionality was evaluated by using LysM domain-containing protein autolysin p60, which targets bacterial peptidoglycan. Specific binding to Nod factors and chitin oligosaccharides was observed, with increasing affinity corresponding to increasing chitin oligomer length.

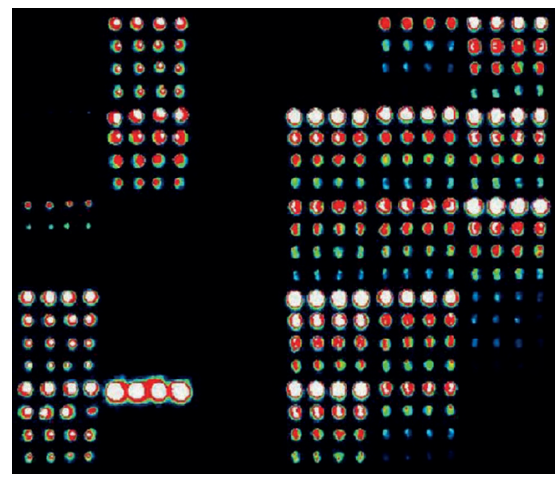

N. N. Maolanon, M. Blaise, K. K. Sørensen, M. B. Thygesen, E. Cló, J. T. Sullivan, C. W. Ronson, J. Stougaard, O. Blixt, K. J. Jensen*

Lipochitin Oligosaccharides Immobilized through Oximes in Glycan Microarrays Bind LysM Proteins 